\title{
La casuística de los juegos de azar y de los espectáculos públicos en el Siglo de Oro
}

\author{
Strosetzki, Christoph
}

First published in:

Teatro espanol del Siglo de Oro, S. 322 - 343, Vervuert Verlag, Frankfurt am Main 1998 ISBN 3-89354-457-7

Münstersches Informations- und Archivsystem multimedialer Inhalte (MIAMI) URN: urn:nbn:de:hbz:6-62439483025 


\section{La casuística de los juegos de azar y de los espectáculos públicos en el Siglo de Oro}

\section{Christoph Strosetzki}

Los juegos son formas institucionalizadas de esparcimiento o de entretenimiento. Se puede distinguir entre juegos de sociedad dentro de un grupo reducido y espectáculos dentro de un ámbito mayor, como por ejemplo, las corridas de toros o el teatro. Elevando el juego al estatus de rasgo característico del ser humano, frente al «homo sapiens» ha situado Huizinga un "homo ludens» movido por la afición al juego en todas las épocas ${ }^{1}$. En el Renacimiento y en el Barroco el juego gozó de especial popularidad ${ }^{2}$. En Góngora y en Quevedo el juego es objeto de sátira, mientras que Cervantes se sirve del vocabulario del jugador con frecuencia. El juego de cartas no sólo se asocia con la cartomancia, sino también con un propósito didáctico o religioso como "naipes a lo divino", o bien se utiliza para ilustrar materias panegíricas, morales o bíblicas. Un ejemplo de la popularidad de las cartas es el "Juego de naypes", de Fernando de Torres, en el cual el autor se vale de figuras del juego de cartas para estructurar su obra, por lo que ésta presenta más las características de un juego que las de un texto ${ }^{3}$.

El trabajo se considera en el Siglo de Oro como una virtud; la inactividad, como un vicio. El ocio se encuentra a medio camino y es virtud o vicio, según sirva como descanso del trabajo o degenere hacia la inactividad. Pero ¿cuándo y bajo qué circustancias se convierte la virtud en vicio, el ocio en inactividad? A comienzos de la Edad Moderna son numerosos los tratados que en España intentan resolver esta pregunta, cuya respuesta implica conclusiones en cuanto a la valoración del comportamiento general en relación al tiempo libre. Los mismos argumentos en pro o en contra del juego se aplicarían finalmente al teatro, a las corridas de toros, las reuniones de baile, la cartomancia y a los chistes del bufón. En la medida en que la dignidad del trabajo se presente como

1 Johan Huizinga, Homo ludens. Vom Ursprung der Kultur im Spiel, Hamburg 1958, págss. 11-14.

2 Compárese Philippe Ariès, Jean-Claude Margolin (ed.), Les jeux à la Renaissance, Actes du XXIII colloque internacional d'études humanistes, Tours - Juillet 1980, Paris (Vrin) 1982; Jean-Pierre Etienvre, Figures du jeu. Etudes lexico-sémantiques sur le jeu de cartes en Espagne (XVI $-X V I I I^{e}$ siècle), Madrid (Casa de Velázquez) 1987.

3 Compárese Jean-Pierre Etienvre, Márgenes literarios del juego. Una poética del naipe, London (Tamesis) 1990, págs. 16-17. 
algo incuestionable podrá justificarse sólo hasta cierto punto el tiempo libre. La argumentación moral se completa aquí con otra económica, en la cual se compara la remuneración del trabajo con las ganancias del jugador, sobre cuya legitimidad se debe decidir de forma diferente, según los casos.

En la antigua Grecia se designaba la ocupación con lo necesario, el trabajo, como "ascholesthai" (no tener tiempo), mientras que el tener tiempo, el tiempo libre, el tener tiempo para sí mismo, se denominaba "scolazein". La palabra "schole» está emparentada con ésta última, de la cual se ha derivado la palabra alemana "Schule", que en este sentido debe entenderse como "otium cum litteris». Fritz Schalk concluye que: «En el ocio no tiene lugar lo accidental, sino lo principal, se tiene tiempo, una vez liberado de la preocupación de lo material, para aquello que importa [...]»4. Frente a esto, Aristoteles ${ }^{5}$ no considera que el descanso sea el verdadero sentido de la existencia humana, sino una interrupción del trabajo para recuperar fuerzas. Por lo tanto, se debe jugar para poder trabajar como corresponde. El descanso excesivo se condenaba en la Antigüedad tardía como "otiositas" y se relacionaba con cualidades como "acedia", "taedium et anxietas cordis", "tristitia et amaritudo immoderata" y "molestia". Así, para Fray Luis de León en "La perfecta casada" es la "vida ociosa" de los caballeros y señores una forma de vida mucho más peligrosa que el trabajo del resto de los grupos sociales 6 . La perspectiva social aparece también en primer plano allí donde se considera el juego como peligro para la conservación del conjunto del Estado. Jerónimo Castillo de Bobadilla aconseja a los jueces y a aquellos que gobiernan sobre vasallos que prohíban el juego no sólo a los artesanos, sino también a los soldados y a los campesinos, bajo la amenaza de ser castigados. Finalmente, sería el juego "padre de la ociosidad, maestro de la pereza, instrumento de la auaricia, fragua de las fraudes, dissipador de la hazienda, y del tiempo, oluido de la familia, y de los amigos, ocasion de ruydos y pendencias, de blasfemias, y corrup-

4 Fritz Schalk, “Otium im Romanischen», en: Brian Vickers (ed.), Arbeit, Muße, Meditation. Betrachtungen zur Vita activa und Vita contemplativa, Zürich (Verlag der Fachvereine $Z$ ürich) 1985 , págs. 225-256, aquí pág. 228.

5 Aristotelis Ethica Nicomachea, X,6, 1176b; I. Bywater (ed.), Oxford (University Press), págs. 211-212.

6 Fray Luis de León, «La perfecta casada», en: Obras completas castellanas, tomo I, Madrid (Editorial Católica) 1951, pág. 262 (Biblioteca de Autores Cristianos); compárese Fritz Schalk, en el lugar citado, pág. 250. 
cion de costumbres, mancha de la dignidad, ignominia insigne, congoxa de espiritu, y fatiga continua»?.

\section{Juegos de fortuna}

Desde la Edad Media, hubo en España una literatura jurídica referida al caso concreto de los juegos de azar. La autoridad estatal tuvo que enfrentarse, ante la necesidad de una regulación, a dos intereses contrapuestos. Por un lado, era lógico prohibir los juegos de azar por razones de política del orden, para evitar el endeudamiento y la ruina de los jugadores. Por otro lado, los juegos de azar suponían una fuente de ingresos debido a los impuestos. Ante este conflicto de intereses, se decidió concentrar los juegos de azar, al igual que la prostitución, en determinados locales que pudieran ser controlados en materia de orden y de impuestos a través de concesion y privamiento de concesiones. Ya en el año 1276 se redactó el "Ordenamiento de las tafuerías", una ley sobre el orden en las casas de juego redactada por el jurista Roldán por orden del rey Alfonso X el Sabio de Castilla, por la cual se reconocía un monopolio local a sus propietarios. La clase superior noble y acomodada no estaba, sin embargo, obligada a respetar este monopolio ${ }^{8}$. La legalización de una de estas casas de juego implicaba también numerosas regulaciones,tales como, por ejemplo, sobre las cantidades de apuesta autorizadas y las prohibidas, sobre posibles delitos y sus penas.

La prohibición del juego por dinero y la exclusión de la posibilidad de poder presentarse ante la justicia para obtener el cobro de ganancias no son nuevas, sino que se remontan al Derecho Romano. En la Edad Media, se prohibieron desde un punto de vista religioso los juegos de azar no sólo porque podían inducir al pecado, sino también porque jugar por dinero era algo no cristiano. Por ello, los sínodos españoles prohíben desde el siglo XI el juego a los clérigos. Para así preservar su recogimiento se prohibió también a los prelados en las Partidas de Alfonso X so pena de ser castigados, la asistencia a torneos o corridas de toros, así

7 Jerónimo Castillo de Bobadilla, Política para corregidores y señores de vasallos, Madrid (Luis Sánchez) 1597, pág. 565.

8 Compárese Eugen Wohlhaupter, "Zur Rechtsgeschichte des Spiels in Spanien", en: H. Finke (ed.), Spanische Forschungen der Görresgesellschaft, Erste Reihe, Gesammelte Aufsätze zur Kulturgeschichte Spaniens, Münster (Aschendorff) 1931, 3, págs. 55-128, aquí pág. 101; para el "Ordenamiento de las tafuerías" de Alfonso, compárese también Dwayne E. Carpenter, "Fickle Fortune: Gambling in Medieval Spain", en: Studies in Philology, LXXXV, summer 1988, nr. 3, págs. 267-278. 
como la participación en juegos de dados o de tablero ${ }^{9}$, ya fuera como jugadores o como espectadores.

En la España medieval, los "tahures" constituían el grupo de los jugadores profesionales y normalmente poco honestos, e iban, al igual que los "juglares", de un lugar a otro, siendo bienvenidos tanto en las cortes de los obispos como en la de los príncipes laicos. Son comunes a "tahures" y ujuglares" las cualidades de entretener al público mediante todo tipo de representaciones y de suscitar la aversión contra todo tipo de trabajo normal. Por lo tanto, se puede comparar perfectamente la virtuosidad de estos "tahures", que se enriquecen gracias a una reserva de trucos bien provista, con la destreza de juglares y «bufones".

Son las ciudades las que decretan prohibiciones contra el juego antes que los señores territoriales. Utilizando medios penales intentaban persuadir en contra del juego, y crearon, valiéndose de medios civiles, un espacio sin jurisdicción, en el que el ganador se encontraba tan indefenso como aquel que no podía exigir que el dinero prestado con motivo del juego le fuera devuelto como deuda de préstamo. En el siglo XV, los señores territoriales prohibieron también las "tafuerías" (casas de juego), aunque la prohibición no se respetó en todos los lugares. Los Reyes Católicos prohibieron los juegos y las casas de juego en las Cortes de Toledo de 1480, pero hicieron una excepción con los juegos de fortuna cuya apuesta no excediera el precio de una comida. La inseguridad jurídica motivada por las constantes regulaciones, que ni concordaban entre sí ni eran, por otra parte, sistemáticas, dio lugar a la demanda de recopilaciones jurídicas. La "Nueva Recopilación" de Granada de 1499, por ejemplo, se ocupaba del modo de castigar el juego ilegal. Ante el hecho de que se empezase a jugar al juego de la pelota, todavía autorizado, con una apuesta elevada, prohibió Carlos I en 1528 todos los juegos "a crédito o a fiado". Las multas, sin embargo, vencían tras sólo dos meses de cometido el delito, lo que puede ser considerado como un suavizamiento de la prohibición ${ }^{10}$.

Los tratados humanistas y filosófico-morales del siglo XVI parten de la inseguridad promovida por las leyes contradictorias e intentan proporcionar una nueva seguridad, basándose en la tradición teológica y en la

9 Esto no le impidió escribir a Alfonso X un libro sobre el juego del ajedrez: Alfonso el Sabio, Libros de Acedrex, dados e tablas. Das Schachzabelbuch König Alfons des Weisen, nach der Handschrift J.T.6 Fol. des Escorial, mit Glossar und grammatischem Abriss, Arnald Steiger (ed.), Genf (Droz) und Zürich, Rentsch, 1941 (Romanica Helvetica 10).

10 Compárese Eugen Wohlhaupter, en el lugar citado, págs. 115, 86, 91, 113. 
tradición de la Antigüedad. El juego aparece en primer lugar como el prototipo de ocio que se contrapone al trabajo. El franciscano Francisco de Alcocer no critica por ello en su "Tratado del juego" (1559)11 el juego como tal, sino su exageración. El objetivo de su tratado es señalar, partiendo de una tipología diferenciada, cúando el juego es permisible y cúando no.

Como el hombre sufre fatiga desde el pecado original tras actividades corporales y espirituales, necesita descansar "para poder pasar adelante y no dar con la carga en tierra»12, según Alcocer. Basándose en Ovidio, se postula el descanso como condición para la subsistencia. Por ello, el "plazer" y el "descanso", al igual que el juego, no serían perjudiciales, sino beneficiosos dentro de un uso moderado, en el momento adecuado y en el lugar correspondiente, lo cual corrobora Alcocer con ejemplos y citas de la Biblia, de autores de la Antigüedad, de padres de la Iglesia y de Tomás de Aquino. Al ser los trabajos espirituales más fatigosos que los corporales, podrían los estudiantes, los intelectuales y los profesores, los clérigos y los predicadores, hacer uso del juego como descanso con mucho más derecho que un trabajador manual.

El mal uso del juego llevaría, sin embargo, a desatender los Diez Mandamientos, y traería consigo codicia, ira, soberbia, envidia, gula y pereza. El juego movería también a consultar a astrólogos, a aceptar pactos con el diablo, a leer en los anillos valiéndose de artes oscuras para obtener así suerte en el juego, a proferir juramentos movidos por la ira, o a que se dediquen los domingos y días de fiesta sólo al juego, olvidando su fin verdadero. El detalle de la pérdida de tiempo precioso durante el juego es el primer y más importante argumento que Alcocer esgrime para prevenir contra el juego desmesurado. A esto se añadiría el sometimiento creciente del jugador bajo la soberanía de los dados, su irresponsabilidad y su desacreditamiento social. La contemplación de la creación mostraría que seres tan irracionales como las hormigas están siempre trabajando ${ }^{13}$. El derroche de tiempo y la amoralidad aparecen, por tanto, como los mayores peligros del juego. Para Alcocer es todavía más importante la diferenciación entre distintos tipos de juegos. En primer lugar, menciona los juegos completamente justificables, ujuegos deuotos y santos" en días de fiesta religiosa o no, "en que se suelen representar algunas historias de la sagrada escritura, o algunas farsas

11 Francisco de Alcocer, Tratado del juego, Salamanca 1559 (Biblioteca Nacional de Madrid R 6636).

12

Ibid., pág. 2.

13 «y que la criatura racional criada a imagen y semejança de Dios se ocupe en cosas tan ociosas y vanas como son los juegos.» Ibid., pág. 19. 
devotas de la tal festiuidad»14. Un segundo tipo lo constituyen los espectáculos controvertidos "en los quales se representan torpes cosas y desonestas y prouocatiuas de luxuria, como lo vsa la gente profana y mundana, en farsas y exercicios y fiestas temporales» 15 . El tercer grupo lo componen los juegos en el sentido más estricto. Proporcionan placer y ocio y se dividen en tres subgrupos: primero, los que están relacionados con el arte, el ejercicio y la aplicación, como el juego de pelota, el ajedrez, el lanzamiento de lanza o la lucha; en segundo lugar, los juegos de azar, como el juego de dados o el de cartas, que se basan en la suerte; y en tercer lugar, los juegos en los que se relaciona el azar con la habilidad.

En la argumentación restante, Alcocer se ocupa de los juegos en su sentido más estricto. A la heterogénea regulación disponible, tanto civil como eclesiástica, de las distintas regiones de España, opone la ley natural, para él teológicamente fundamentada. La convierte en norma para valorar el juego, aunque presente y comente el derecho positivo repetidas veces. También proporciona ejemplos en los que el derecho consuetudinario ha superado al derecho positivo ${ }^{16}$. El que sólo juega de vez en cuando puede haber infringido la ley positiva, pero actúa legítimamente ${ }^{17}$. Aun cuando las leyes estatales prohíban el juego, se podría disculpar al jugador que actúa por desconocimiento de dichas leyes, siempre que éste juegue con apuesta reducida y para entretenerse. Alcocer se muestra también especialmente generoso en la cuestión de si los clérigos pueden jugar, y proporciona casos en los que está permitido como, p. ej., en caso de descanso, o con la intención de proporcionar un placer a otro.

La mayor parte del libro se refiere a la discusión de los distintos casos de apuesta y ganancia. Con ello se intenta cubrir moralmente y según la ley natural el espacio que el derecho positivo desatiende consciente y constantemente. Así, se tendría la obligación de devolverle lo ganado a las personas que no pueden enajenar sus posesiones. A este grupo de personas pertenecen los menores de edad y las mujeres casadas, así como los clérigos. Sería una falta moral cuando la cantidad de dinero

14 Ibid., pág. 27.

15 Ibid., pág. 27.

16 Por ejemplo, las regulaciones sobre exigencias de devolución de lo perdido y lo ganado o sobre el juego en días de fiesta.

17 «No pecan mortalmente por razon del derecho commun que veda los juegos; porque las tales leyes estan derogadas y abrogadas por la costumbre, que ha dexado el juego en los terminos del derecho diuino y natural." Francisco de Alcocer, en el lugar citado, pág. 61 . 
fuera mayor o el juego tuviera lugar no como diversión, sino por afán de lucro. Pero sobre todo se plantea la cuestión de si están obligadas a devolver la ganancia las personas que no pueden enajenar nada y que ganan en juego con personas que sí pueden dispendiar sus bienes. Alcocer discute además detenidamente el problema sobre el que insisten también los padres de la Iglesia, de si la igualdad, la superioridad o la insignificancia de la apuesta son decisivas. Como las ganancias obtenidas por engaño deben ser siempre devueltas, Alcocer pregunta si no se presentan situaciones en las que el engaño es parte del juego. ¿Tiene que devolverle el ganador al perdedor la apuesta, cuando éste le ha inducido al juego? Como los padres de la Iglesia no coinciden en este punto, Alcocer hace depender la respuesta de la insistencia más o menos firme del inductor. Si los jugadores pueden disponer libremente de sus bienes y no se registra engaño o violencia, el derecho natural permite que los jugadores conserven la ganancia.

Además, se discute si es necesaria una devolución cuando la ganancia es movida por la codicia, cuando se trata de juegos prohibidos en la región correspondiente, cuando el ganador ha ganado con dinero prestado o el perdedor ha perdido con dinero prestado, cuando la ganancia supera una cantidad concreta o cuando se ha jugado con un clérigo. Otras preguntas son si se pueden equilibrar las ganancias con las pérdidas o si se pueden dar a los pobres las ganancias de juegos prohibidos. ¿Si una mujer casada, cuya propiedad no puede enajenar, le presta dinero a un jugador, debe devolverse también la ganancia de éste? Alcocer incluye, por lo tanto, en su causística a los participantes indirectos del juego. Entre estos se encuentran los que producen, venden, prestan o alquilan los dados, cartas y otros utensilios necesarios para el juego. Su actividad sería neutral mientras desconozcan que sus clientes tienen malas intenciones, ya que el juego en sí no sería nocivo: «la culpa es de los que vsan mal de estos instrumentos, y no es de quien los haze»18. Los promotores de garitos de juego hacen el juego posible siempre que faciliten una casa y utensilios para el juego, aconsejen el juego a los jugadores y presten dinero, por lo que pueden ser considerados como causa. A raíz de ello se plantea la pregunta de si son también responsables de todos los actos del jugador. Si el promotor del garito tiene culpa y debe devolver el dinero, depende, según Alcocer, de la magnitud de los daños cometidos.

Un valor parecido al juego tienen las «suertes». Con esto se hace referencia a métodos con los cuales se averigua algo sobre el futuro o un secreto, y en los que se deja decidir al azar. Se puede, p. ej., sacar un número o abrir un libro en un lugar determinado, cuyas primeras letras se 
toman como un indicio de lo que se busca. Había incluso libros en los que las ilustraciones y los dichos estaban dispuestos de tal forma que utilizando unos dados se podía acceder desde un punto de partida a otro final, cuya ilustración o dicho ofrecía la respuesta a la pregunta inicial ${ }^{19}$. Alcocer querría que este tipo de "suertes" estuvieran prohibidas sólo en relación con «algun vicio de vanidad, codicia, prodigalidad o otra causa de las que se pusieron tractando de los juegos y apuestas»20. Sería muy juicioso, sin embargo, repartir limosnas o títulos terrenos o cargos por medio de estas "suertes".

Otras formas de diversión se enjuician, al igual que el juego, según el criterio de la magnitud del daño y de la moral. De este modo, se denomina a los comediantes y cabaretistas ugente vagabunda, ociosa y perdida» 21 , que dicen banalidades y maldades, que cultivan las murmuraciones contra gente honesta y que no sólo representan chistes inofensivos, sino que también hieren el honor y la honra de otros. Sin embargo, Alcocer opina que aquellos que realizan mal este oficio no proporcionan razón alguna para condenarlo: "porque como el juego es necessario para aliuio de los trabajos desta vida, asi lo es oyr dezir algunas gracias y donayres» 22 . Pero no se debería llenar de regalos y mimar este tipo de oficio. Se debería regalar antes a los pobres, que se mueren de hambre y frío.

Las corridas de toros son para Alcocer otra forma permisible de pasar el tiempo. Esto es válido únicamente cuando el posible daño se mantiene controlado, es decir, cuando ningún torero corre peligro de morir en la arena. Si no se pudiera garantizar la ausencia de peligro, habría que divertirse con otros juegos, como las ujustas", "correr sortija" o "esgrimir". Otra alternativa sería el baile, que también parece permitido en las fiestas, incluso cuando se dedica mucho tiempo a ello. Que se pueda llevar máscaras depende de quién las lleve y con qué intención. Para representaciones escénicas serían muy oportunas. "Las representaciones de farsas y inuenciones es otra manera de regozijo y juego» 23 . Como ya se ha mostrado en la clasificación de los tipos de juegos según Alcocer, las representaciones religiosas se permiten en igual medida que las denominadas "farsas»: «historias passadas que los poetas cuentan, y otras de fingidas: las quales como no aya en ellas cosas tan desonestas que sean

19 Compárese Rosa Navarro Durán (ed.), Libro de las suertes/anónimo, Madrid (CSIC) 1987, 2. Ed.

21 Ibid., pág. 279.

22 Ibid., pág. 280.

Ibid., pág. 301. 
de suyo prouocativas à pecado mortal, no ay efficaz razon para las condenar" 24 . Esto no sería aplicable cuando se representen cosas que sean repelentes o enemigas de la Iglesia, según Alcocer, que repite con ello los criterios usuales de la censura literaria de la Inquisición.

Si bien se puede afirmar que en el juego de cartas o en el de dados los participantes toman parte de forma activa, éste no es precisamente el caso de las diversiones mencionadas en último lugar. Por ello Alcocer se refiere también al público, a los que participan como espectadores en “juegos, iustas, torneos, farsas, representaciones y otros regozijos» 25 . Mientras que su comportamiento en condiciones normales le parece legítimo, se convierte para él en una falta leve cuando le dedican mucho tiempo y en una falta grave, cuando por ello desatienden sus obligaciones. También los gobernantes serían responsables y deberían estar atentos a los gastos de tiempo y de dinero de los espectadores. Se debería prestar especial atención a las fiestas de varios días ${ }^{26}$. En general, la valoración del espectador depende de la diversión correspondiente. Si ésta es aceptable, entonces el espectador no cometería falta alguna. A la inversa, sería válido que: "Todo aquel que se deleyta del pecado mortal ageno, peca mortalmente» 27 . De todos modos, dependería de la intención del espectador: No sería culpable si no se regocija en los pecados mortales expuestos, sino que se concentra en los elementos permitidos de la representación como, p. ej., el giro del toro o los movimientos elegantes del torero.

Como en Alcocer, en Cobarrubias, que publicó en 1543 un «Remedio de jugadores", la relación correcta con el tiempo constituye también el punto de partida de la argumentación ${ }^{28}$. Cobarrubias divide su libro en tres partes: En la primera, presenta los juegos beneficiosos y permitidos; en la segunda, los prohibidos y dañinos; en la tercera, se refiere a la devolución de la ganancia. Como Alcocer, completa su argumentación en capítulos concretos con la regulación en derecho canónico y civil. Justi-

24 Ibid., pág. 302.

25 Ibid., pág. 319.

26 «Porque son las gentes tan ligeras y vanas, que en auiendo algun regozijo y fiesta procuran entrar en ella y gastar mas de lo que razonablemente pueden." Ibid., pág. 320.

27 Ibid., pág. 322.

28 “Y porque el tiempo de la presente vida es en el qual nos podemos saluar y no despues: perderle es perdernos. Por esso dixo Seneca ninguna cosa es tan nuestra como el tiempo: todas las otras cosas son agenas solo el tiempo es nuestro." Fray Pedro de Cobarrubias, Remedio de Jugadores, Salamanca 1543, pág. III, (Biblioteca Nacional de Madrid R 31413). 
fica, recurriendo a Aristóteles, “juego, deporte, passatiempo»29 en general como recurso de descanso frente al trabajo. Por lo tanto, en los días de fiesta no serían preceptibles los juegos en los que uno no descansa, sino que se fatiga. Por el contrario, serían aconsejables: «dançar, jugar a la pelota, justar y otros passatiempos semejantes: trastornar libros: escrebir sermones: y otros muchos semejantes ordenados a lo espiritual»30. También aquí se considera el juego en el contexto de otras actividades de tiempo libre posibles.

Como el ajedrez requiere mucho tiempo, sería inadecuado para aquellos que estén muy ocupados. "Este passatiempo no es sino para los muy ociosos ingenios por redemirlos de malos pensamientos o para los congoxados que dessean desaisir la mente de algun gran cuydado que les da pena, y trabajo»31. A continuación, Cobarrubias discute sobre el sentido y la legitimidad del baile, de las apuestas, de los festejos, de la música, de los duelos, de las fiestas de máscaras y de la caza. Su valoración depende del lugar, del momento y del grupo de personas participante.

Cobarrubias discute, al igual que Alcocer, la cuestión de bajo qué circustancias se debe prohibir el juego de azar refiriéndose a los vicios que éste conlleva. Él optaría por prohibir los juegos que insulten, hieran o se burlen del prójimo ${ }^{32}$. Partiendo de la interacción social individual, busca el significado político-social del juego. "Ansi que todos somos obligados de tener y viuir y seruir de algun officio, trabajo, o industria espiritual, o temporal prouechoso a la republica. El juego es exercicio occioso no pruechoso al bien público antes dañoso: pues luego siguese que no es licito vsar del»33. Esto no sería válido, según Cobarrubias, cuando se trate de descanso del trabajo ${ }^{34}$. Tanto en él como en Alcocer se percibe, pues, que el juego debe ser justificado, como alternativa al trabajo en vistas a las malas costumbres que puede acarrear. La complejidad que se deriva de la temática es responsable de que el juego se discuta no sólo en los correspondientes tratados monográficos, sino también como caso concreto en textos humanistas y teológicos generales.

29 Ibid., pág. VII.

30 Ibid., pág. XXII.

31 Ibid., pág. XIII; para las capacidades necesarias para el juego del ajedrez y su relación con el arte de la guerra compárese: Huarte de San Juan, Examen de ingenios, Guillermo Serés (ed.), Madrid (Cátedra) 1989, págs. 408-409, 546 y sig., 563-564.

Cobarrubias, en el lugar citado, pág. XXXVI.

33 Ibid., pág. XXXIX.

34 "Assi mesmo para que el exercicio o qualquier obra sea licita no es menester que de directo sea prouechosa a la communidad: vasta que de su naturaleza no sea mala, ni dañosa a otro." Ibid., pág. XXXXX. 


\section{Contexto religioso y humanista del juego}

El fraile franciscano Diego de Estella (1524-1578) minimiza lo terrenal en su "Libro de la vanidad del mundo" (1562), para así realzar todavía más lo trascendente. Cuando utiliza el concepto de "santa ociosidad»35, lo hace sólo para realzar el hecho de que la lectura de libros devotos o la asistencia a la misa es en realidad trabajo, el cual debe ser mucho más valorado que el trabajo cotidiano. Con ello relaciona la preferencia de lo espiritual frente a lo corporal y la de la actividad frente a la pasividad. Además, rechaza placeres que le parecen superficiales: "Así todos los regalos y deleites del mundo en lo exterior son blandos y suaves, y en lo interior tan pestilenciales y mortíferos, que el que los quiebra muere para siempre. [...] Así los que viven en deleites, como mordidos de esta maldita serpiente, duermen hasta el mediodía, y gastan la vida ociosamente, comiendo y bebiendo y durmiendo como animales»36. Como epicúreo trata de forma despectiva a los que opinan que pueden aparentar majestad y conciencia de clase por medio de grandes banquetes y fiestas. Para él los placeres mundanos son físicos y bloquean el acceso a Dios $^{37}$. El ocio unido a placeres del cuerpo aparece más bien como pérdida de tiempo, que es más precioso que el oro, puesto que una vez gastado no puede volver a adquirirse.

Diego de Estella considera el movimiento como positivo, el reposo como negativo. Así, mientras que el agua en movimiento lleva consigo buenos peces, el agua estancada ofrece sólo ranas, culebras y peces repelentes. "Todos los metales, piedras preciosas, licores, voces, instrumentos, fuerzas humanas, ingenios, la ociosidad los destruye y el uso los adoba y afina. Hasta el hierro, si se trabaja, se alisa y hácese resplandeciente y lustroso. Los elementos no están un momento ociosos, los cielos siempre se mueven, y los planetas producen sus frutos. Sólo un monstruo hay en el mundo, y éste es el hombre ocioso»38. Diego de Estella propone, con vistas al juicio final, que se compruebe, "si de una sola palabra ociosa has de dar cuenta y raz6n» ${ }^{39}$. Para ello se basa en la Biblia y cita la frase de Mateo: «En verdad os digo: por cada palabra innecesaria, que

35 Fray Diego de Estella, Libro de la vanidad del mundo, Pio Sagües Azcona (ed.), Madrid (Editorial franciscana "Aranzazu») 1980, pág. 685.

36 Ibid., pág. 162.

37 «Es el ánima inclinada a obras de virtud, y el hombre tiene de su naturaleza usar de razón; pero contradícele el cuerpo, que ama estas cosas sensibles.» Ibid., pág. 674.

39 Ibid., pág. 681. 
los hombres dicen, tendrán que responder en el juicio final»40. Utiliza a Job $(5,7)$ con la frase: «El hombre nace para trabajar, el ave, para volar»; a Mateo $(7,19)$ con la amenaza: «El árbol que no hace fruto será cortado y echado al fuego del infierno". Se vale asimismo del Libro de la sabiduría $(10,10)$ con la afirmación: "Llevó Dios al justo por los caminos derechos, y adornólo con trabajos", de Horacio4i con "Nunca se hubo grande cosa sin trabajo», de Aristóteles ${ }^{42}$ con «las cosas que con él se alcanzan dan más gusto»43. Por fin, lo que importa son "las buenas acciones». Pero éstas no se pueden conseguir a través del ocio.

El intelectual y cosmógrafo Pedro de Medina (nacido en 1493) se refiere también en su "Libro de la verdad", a la hora de considerar el juego, a la utilización correcta del tiempo. Mientras que comprende el ocio como ganado descanso después del trabajo para recuperar fuerzas, la ociosidad, la pereza son comparables con la muerte. El ocio podría ser la base de grandes hechos y de la fama, la ociosidad y la pereza implican únicamente cosas negativas: "cría luxuria, agrava el cuerpo, enflaquece el ánimo, ofusca el ingenio, diminuye el saber, apaga la memoria, pare olvido»44. Por el contrario, en la noche se despiertan o se levantan aquellos que, como los reyes, los príncipes, los capitanes o los sabios, tienen responsabilidades. Esto sería igualmente útil para la vida, la salud, la riqueza y la fama. "Y por esto así como el sueño es llamado de algunos muerte, así los sabios el velar llaman vida. Pues entre la muerte y la vida mira tú qué diferencia hay, y cuál debes elegir" 45 . Aquí se muestra, como en Diego de Estella, la ociosidad como una completa pasividad, opuesta a la actividad. En este contexto, se hace comprensible la repulsa contra el juego de Pedro de Medina. El juego supondría un despilfarro de tiempo precioso, que ya no se podría utilizar para el trabajo 0 para «obras santas de virtud"46, y supondría asimismo malgastar las facultades personales. El jugador habitual sería un loco porque habría perdido su capacidad de razonar y se sometería al juego de manera tal, que parecería que imitara a los infieles adorando a sus ídolos. El

40 Mateo $(12,36)$.

41 Horacio, Satirae I, 9, 59-60, Karl Büchner (ed.), Bologna (Editoriale Pàtron) 1970, pág. 164.

42 Aristotelis Ethica Nicomachea, X,4, 1174b, 31-32; I. Bywater (ed.), Oxford (University Press), págs. 207.

43 Fray Diego de Estella, en el lugar citado, págs. 682-684.

44 Pedro de Medina, Obras I, Angel González Palencia (ed.), Madrid (CSIC) 1944, pág. 295-296.

45 Ibid., pág. 296.

46 Ibid., pág. 297. 
erasmista Jerónimo de Mondragón en su «Censura de la locura humana y excelencias de ella" (1598) se refiere también a los jugadores como a unos locos. Parece que han perdido el juicio, o que no lo tuvieron nunca, porque se destruyen con el juego, que no proporciona ningún tipo de placer. Mondragón cita como ejemplo el caso de un jugador, que tras haber jugado por la noche vuelve a casa y maltrata a su mujer, la cual trabaja durante el día como una esclava. Igualmente conocido sería que en los puertos muchos jugadores terminarían por sus altas apuestas como galeotes, teniendo que trabajar entonces encadenados. Otros, por otro lado, habrían pactado con el diablo para poder ganar.

La sátira del jugador, tomando como base el "Elogio de la locura» de Erasmo, era en la literatura humanista un ejercicio literario bastante extendido. En los satíricos "Coloquios» (1553) del humanista Antonio de Torquemada (1530-1590), que se basan en las argumentaciones de los tratados moralistas sobre el juego, tal y como ha demostrado Lina Rodríguez Cacho, aparecen el juego de los frailes y los perjuicios del juego para el honor como puntos de interés. Torquemada critica también la codicia y la ambición, enumera los males y los peligros para el cuerpo y el alma ligados al juego y pregunta retóricamente, si podría él añadir algo nuevo, en vista de lo minucioso de los tratados existentes. Rodríguez Cacho considera la novedad sobre todo en función de la forma. El diálogo entre el jugador Bernardo, que se acaba de retirar de una partida perdida, y Antonio, que a consecuencia de males anteriores acarreados por el juego se ha vuelto inteligente y razonable, hace posible una separacion entre la perspectiva del protagonista inexperto y del narrador experimentado, que recuerda la bifurcación del "yo" de la novela picaresca. Esto reduce la distancia existente en la literatura tratadista entre el autor y el lector y permite una cierta complicidad entre el moralista y el receptor 4 .

Como la pérdida de sentido de la realidad ligada al juego convierte a los jugadores en objeto de la sátira y los hace aparecer como unos locos, aconsejan expresiones tópicas y refranes contemporáneos que se ahorre tanto con el juego como con el sueño. El sueño, el juego y el paseo aparecen relacionados con el ocio. Precisamente dice un exhortativo refrán: "Sueño, juego y passear, sólo para recrear»48. Luis Vives persigue también fines pedagógicos en sus diálogos latinos "Linguae Latinae Exercitatio" (1538), donde enumera al final del diálogo 22 seis reglas

47 Lina Rodríguez Cacho, Pecados sociales y literatura satírica en el siglo XVI: los "Coloquios" de Torquemada, Madrid (Ediciones de la Universidad Autónoma de Madrid) 1989 , págs. $27,31,33,45-47,56$. 
sobre el comportamiento adecuado frente al juego. También en él encontramos en primer lugar el gasto del tiempo para el juego. Como el hombre habría sido creado para grandes cosas y no para bromas o pasatiempos, debería conceder al juego el tiempo necesario para poder recuperarse en cuerpo y alma del cansancio motivado por las cosas importantes. Así, se podría comparar el juego con el sueño o con el comer o el beber, que de igual manera sólo tienen sentido en la medida en que el cuerpo los necesita para recuperar o renovar fuerzas. La segunda regla se refiere a la elección del compañero en el juego, cuya motivación debe ser también el recuperarse, jugar, no entregarse a vicio alguno ni proferir juramentos. Debería tenerse cuidado con compañeros no conocidos. $\mathrm{El}$ resto de las reglas se refieren a la forma del juego. Todos los participantes, también los espectadores, deben conocerlo, porque en caso contrario no produce diversión alguna. El juego debe relajar el espíritu y el alma y dejar menos posibilidades al azar que a la habilidad. Es verdad que un juego sin premio sería aburrido, pero la apuesta debería ser lo suficientemente reducida como para que el juego no se convierta en tortura por el miedo ante la posible pérdida, perdiendo así su fin recreativo. La apuesta no debe superar el valor que se le concede a la recuperación del trabajo y del cansancio. El juego tendría únicamente sentido cuando uno se enfrenta al azar con calma y tranquilidad y no pierde los nervios cuando pierde. El juego debería finalizar cuando se ha descansado y se está otra vez preparado para los "negocios serios" 49. Los juegos de fortuna son considerados también por el humanista Vives principalmente como descanso del trabajo. Tanto en los textos religiosos como en los humanistas hay acuerdo, pues, acerca de la valoración del juego. En vistas a ello se plantea la pregunta de si el sentido y el fin del teatro que es calificado de juego también se considera de forma similar en la literatura tratadista. 50

Luis Vives, Diálogos sobre la educación, Pedro Rodriguez Santidrián (ed.), Madrid (Alianza) 1987, pág. 185; sobre la clasificación de los juegos en Vives, uexercitationes corporis", ulusus puerilis», "ludus cartarum seu foliorum "y upila» compárese: Roland Renson, "Le jeu chez Juan Luis Vivès (1492-1540)", en: Philippe Ariès, Jean-Claude Margolin (ed.), Les jeux á la Renaissance, Actes du XXIII colloque internacional d'études humanistes, Tours - Juillet 1980, Paris (Vrin) 1982, págs. 469-487, aquí pág. 475.

50 Compárese Marc Vitse, Eléments pour une théorie du théâtre espagnol du XVII siècle, Toulouse, PUM 1990, págs. 29-83; Ignacio Arellano, Historia del teatro español del siglo XVII, Madrid (Cátedra) 1995, págs. 140-146. 


\section{Teatro}

El jesuita Juan de Mariana (1535-1624) incluye en su "Tratado contra los juegos públicos» (1609) el teatro, que para él es tan criticable como otras formas de juego. Mariana califica al teatro como "una oficina de deshonestidad y desvergüenza, donde muchos de toda edad, sexo y calidad se corrompen, y con representaciones vanas y enmascaradas aprenden vicios verdaderos» 51 . El teatro promovería la inmoralidad: "porque ¿qué otra cosa contiene el teatro y qué otra cosa allí se refiere sino caidas de doncellas, amores de rameras, artes de rufianes y alcahuetas, engaños de criados y criadas, todo declarado con versos numerosos y elegantes y de hermosas y claras sentencias esmaltado por donde mas tenazmente à la memoria se pega, la ignorancia de las cuales es mucho mas provechosa?»52. Mariana considera el teatro como una institución que haría un uso equivocado del ocio y de la educación para el entretenimiento del pueblo. Mariana iguala a las actrices, que seducen al público hacia formas de vida inmorales, con las prostitutas y los jugadores cuando discute la pregunta de si tendría sentido la concentración de este espectáculo inmoral en una casa para ello dispuesta, y para la concesión de cuya licencia se pudiera recaudar un impuesto que sirviera para ayudar a los pobres. Como las tropas de actores reciben dinero por sus viciosas representaciones, Mariana pretende expulsarlos de la Iglesia y prohibir a los clérigos la asistencia a sus «juegos» y "farsas". En su opinión, provocan también la música y el baile en el teatro sólo pasiones e inmoralidad. Especialmente reprochables le parecen la música y el baile de la Zarabanda. Él atribuye que «juegos, disoluciones, trajes, comidas y banquetes» 53 hayan ganado considerablemente en importancia al bienestar, a la paz y al ocio, que estarían extendidos por todas las clases sociales en España. Como para él el teatro es sólo un elemento en el amplio espectro de ocupaciones de diversión y tiempo libre, se ocupa también de las corridas de toros. Mariana las condena de igual forma porque los espectadores no tienen derecho a entretenerse 0 divertirse con la muerte o las heridas del torero. En resumidas cuentas, reafirma su rechazo contra los espectáculos públicos, los placeres de la caza, los cómicos ambulantes y las prostitutas. Refiriéndose a la historia de Roma, Mariana muestra que un Estado permanece próspero e invencible en la medida en que rechaza a los cómicos y prohíbe las representaciones de teatro. Resumiendo, afirma lo siguiente: «El imperio por

51 Juan de Mariana, "Tratado contra los juegos públicos", en: Obras del Padre Juan de Mariana, t. II, Madrid (Atlas) 1950, (BAE), pág. 413-576, aquí págs. 413.

53 Ibid, pág. 446 
cierto de los persas, la grandeza de los griegos y de los romanos, el ocio, la paz, el descuido los destruyeron"54. También España se habría afeminado con los tesores traídos del Nuevo Mundo. Afán de divertirse, derroche, pérdida de poder, serían las consecuencias de esto.

Una posición opuesta a Mariana representa el monje franciscano Francisco Ortiz en "La apología en defensa de las comedias que se representan en España", que escribió en 1608 o 160955. El teatro supone también para él una forma del juego, al explicar la denominación de «ludiones» para los actores escribe: «'ludus' quiere decir 'juego' y la representación lo es»56. En primer lugar, se refiere en sus argumentaciones a leyes y concilios concretos. Posteriormente añade las opiniones de santos, padres de la Iglesia, teólogos y autores antiguos. En el capítulo sobre los actores refuta la tesis de que estos no tengan honra y sean infames o indignos de la comunión. Con referencia a las obras de teatro de su tiempo concluye que "con razón son alabadas y defendidas de los autores que tengo allegados ${ }^{57}$. Frente a la legitimidad de la asistencia al teatro se plantea la pregunta: $\mathrm{Si}$ el teatro es por principio inmoral, ¿procede inmoralmente aquel que está presente como espectador, al exponerse por lo menos a un peligro no calculado? Ortiz se opone a esto por principio, ya que el teatro sería bueno como tal y sólo podría ser mal utilizado por espectadores maliciosos -al igual que el juego de cartas, al que se refiere especialmente. Para ilustrarlo, cita la "Celestina", con cuya lectura el lector inteligente distingue las sentencias de numerosos filósofos que aparecen en el texto, y saca una enseñanza de él. «Pero si lo lee un ignorante, no entiende lo bueno, y solamente le queda en la memoria la traza que tuvo Calixto para entrar a hablar a Melibea, siendo el intento del libro bien diferente»58. Al igual que los juegos de fortuna, el teatro como tal no debe ser rechazado. Se hace reprochable a través de una actitud receptiva equivocada, por medio de su falso uso.

Es especialmente revelador en este contexto que la medida de la utilización correcta y útil del tiempo destinado al juego es también importante para la valoración del espectador del teatro. También en el caso de que se vaya al teatro para pasar el tiempo, para divertirse, para escuchar versos o para conocer ideas, arguye Ortiz que la vida sin entreteni-

\section{Ibid., pág. 459.}

55 Francisco Ortiz, La apología en defensa de las comedias que se representan en España, Louis C. Pérez (ed.), Chapel Hill, N. C., 1977, págs. 11-12, 123 (Estudios de Hispanófila 45). 
miento es como una comida sin sal ${ }^{59}$. Sin embargo, cuando el estudiante, el jurista, el hombre de negocios u otra persona que debe cumplir con su obligación, desatiende sus tareas para ir al teatro, entonces sí se podría hablar de tiempo perdido. Este no sería, sin embargo, el caso de aquellos que van de vez en cuando al teatro. Aparentemente se utiliza aquí el mismo sistema argumental que legitima al juego como entretenimiento moderado. Aquellos que como los nobles sólo podrían elegir, a pesar de todo, entre distintos tipos de tiempo libre, estarían bien servidos con el teatro: "Con el caballero, con el admirado y paseante, que el rato que no duerme en la cama echa cuenta cómo ha de emplear la tarde en jugar su hacienda, en visitar damas y en rondar calles. Y estos tales no pierden, sino ganan el tiempo empleándolo en la comedia»60. Como el espectador gasta no sólo tiempo, sino también dinero, rechaza también Ortiz la asistencia diaria al teatro por razones económicas. Pero el que vaya al teatro sólo los días de fiesta, puede alegrarse de subvencionar hospitales y de ayudar a los necesitados con su dinero, puesto que una parte de la recaudación se destina a ellos.

Un criterio más estricto se aplica tradicionalmente con las mujeres y con los clérigos. Mientras que las primeras deben presentar un comportamiento ejemplar, deben los últimos ser protegidos. Ortiz cita "La perfecta casada" de Fray Luis de León, donde se narra que las mujeres de reyes y príncipes hilan y cosen. Sin embargo, opina Ortiz, que las mujeres podrían ir al teatro con el mismo derecho que van a la iglesia, ya que en ambos casos abandonan la casa y se muestran públicamente. En primer lugar, habría en algunos teatros accesos separados para hombres y mujeres. Además, se podrían cubrir con vestidos adecuados. En vez de que los hombres se recluyeran durante tres horas en el teatro y dejaran a las mujeres airadas en casa, sería mejor, que ambos sexos pasaran las tres horas juntos en el teatro. Así como los clérigos, cuando no existe una prohibición expresa de sus superiores, podrían también tanto las mujeres como los hombres ir al teatro. Cuando Ortiz distingue entre las distintas posibilidades de distracción, le parece de todos modos mucho más valioso en general el teatro que el juego: «Digo, que considerando lo que ahora pasa y el empleo que hacen los hombres comúnmente del tiempo gastándolo en juegos donde reniegan, juran y blasfe-

59 "Y que siendo así que el tiempo corre y vuela con tan ligeras alas, que más necesidad hay en qué emplearle bien, que de ayudarle a pasar, y que así como sería necesidad de dar en una comida salsas y perejiles y no otra cosa de sustancia con qué comiesen, asi lo es también pasar la vida en entretenimientos, que son las salsas de los trabajos, sin tenerlos en cosa de importancia.» Ibid., pág. 87.

60 Ibid., págs. 87-88. 
man, y con mujeres con quienes se desvanecen, gastan y consumen; me parece que la comedia es un entretenimiento al cual se puede acudir sin pecado" 61 .

El hecho de que L. Vives, J. de Mariana y F. Ortiz no son casos aislados y que el teatro a partir del siglo XVI y hasta el siglo XVIII se considera en la literatura de los tratados como diversión y, por tanto, se encuentra en el mismo nivel que el juego, se manifiesta claramente si se consulta la amplia "Bibliografia de las controversias sobre la licitud del teatro en España" de Emilio Cotarelo y Mori, reeditada en el año 1997.62 En esta bibliografía comentada con extractos de los textos se encuentran citas que lo confirman de D. Melchor de Cabrera y Guzmán ${ }^{63}$, del jesuita P. Ignacio de Camargo64, Fray Jerónimo de la Cruz ${ }^{65}$, del jesuita P. Juan Ferrer ${ }^{66}$ y del jesuita P. Pedro de Guzmán ${ }^{67}$. Frecuentemente se utiliza

61 Ibid., pág. 88.

62 Emilio Cotarelo y Mori, Bibliografia de las controversias sobre la licitud del teatro en España, Estudio preliminar e índices de José Luis Suárez García, Granada 1997 (Edición facsímil de Madrid 1904).

63 «Antiguamente en todos los reynos y provincias se usaron comedias, fiestas, juegos y entretenimientos, á que concurrían los príncipes, los magistrados, los senadores, la nobleza y la plebe, que se hacían ya en teatros diputados para ello, ya en las plaças, ya en los campos y ya en los templos;" D. Melchor de Cabrera y Guzmán, "Defensa por el uso de las comedias, y suplica al Rey nuestro señor para que se continuen (1646)", en: Cotarelo y Mori, pág. 95.

64 Con respecto al traje femenino: «¿Entregados totalmente á fiestas profanas, á músicas, á paseos, á los amores lascivos, á conversaciones ociosas, á juegos y divertimientos vanos, á peinar, trenzar y teñir el pelo, á rizar la cabellera postiza, á pulir y componer el vestido con tanta proligidad y melindre como la dama más delicada?. P. Ignacio de Camargo, «Discurso theologico sobre los theatros y comedias de este siglo (1689)", en: ibid., pág 127.

65 «siendo menester menos dinero para entrar en el teatro que para entrar en la casa del juego." Fray Jerónimo de la Cruz, "Iob evangelico stoyco ilvstrado (1638)n, en: ibid., pág. 204.

66 aAl fin, en conclusión, sean las representaciones y otros juegos y recreaciones de la república de manera y con las circunstancias que dice Santo Tomás y la escuela de los teólogos, y háyalas muy enhorabuena, que á buen seguro que si de esa manera son, no sólo no sean dañosas, sino muy provechosas: serán virtud y no vicio.» P. Juan Ferrer, "Tratado de las Comedias en el qval se declara si son lícitas (1613)», en: ibid., pág. 250.

67 P. Pedro de Guzmán en Bienes de el honesto trabaio y daños de la ociosidad (1614) habla «de la ociosidad, del sueño, de los juegos antiguos, griegos y latinos, de los toros, del juego de interés y de las recreaciones lícitas.» Ibid., pág. 348. 
la palabra de la "eutrapelia" como "honesta recreación»68 o "recreación virtuosa y conversación loable, la cual convierte en pasatiempo algún dicho ó hecho," 69 recurriendo a la Biblia, a la Antigüedad, a la escolástica y a la literatura religiosa más reciente ${ }^{70}$. En la declaración de la Junta superior del año 1672 sobre la licitud de la comedia se afirmó: «La Junta, para hacer dictamen en esta materia, reconoce cuán justos son los motivos políticos de divertir con algunas fiestas ó entretenimientos al pueblo, aliviándole por este medio prudentemente el peso de los ahogos y la melancolía de sus discursos, y que á este fin en todas las repúblicas bien ordenadas se introdujeron fiestas, juegos y regocijos públicos, que siendo con templanza y decencia no los ha condenado nunca ni la censura más estrecha y rigurosa.»71

\section{Resumen}

Se ha mostrado, pues, que el teatro es considerado como un juego y es valorado con los criterios con los que se enjuicia el juego y otras actividades de tiempo libre. Un punto de partida utilizado por la mayoría de los autores lo constituye el predominio aristotélico del trabajo, que considera al ocio como renovación de fuerzas para la actividad y que, por lo tanto, lo subordina a ella. El otro punto de partida lo constituye el concepto cristiano de la antigüedad tardía de la "otiositas", a la que se culpa de acarrear todos los vicios y males posibles. Ambos son utilizados una y otra vez como argumentación contra el juego dentro de un enjuiciamiento de los distintos tipos de tiempo libre, de forma especialmente agresiva contra los jugadores de azar habituales, de forma más débil contra los espectadores del teatro. Mientra que Alcocer cita como posibles fenómenos implícitos a los juegos de fortuna el derroche, la ira, la gula y la pereza, Mariana considera como consecuencia del teatro la inmoralidad, las pasiones, los placeres de la mesa exagerados y el afeminamiento. También se derivan paralelismos entre el espectáculo y los juegos de fortuna de aquel principio de la Antigüedad según el cual se

68 Anónimo, Diálogos de las comedias (1620), en: ibid., pág. 223.

69 Fr. José de Jesús María, «Primera parte de las excelencias de la virtvd de la Castidad (1600)", en: ibid., pág. 371.

70 P. Pedro Fomperosa y Quintana, «La Evtrapelia. medio, qve deben tener los juegos, Divertimientos, y Comedias, para que no aya en ellas pecado y puedan exercitarse lícita, y honestamente. Segun la doctrina de el Apóstol San Pablo, Santo Thomas y San Francisco de Sales (1683)", en: ibid., pág. 268; Fr. Manuel de Guerra y Ribera recurre en 1682 a Aristóteles, Agustín, Tomás de Aquino y Francisco de Sales, cf. ibid., pág. 335.

71 Cf. ibid., pág. 388. 
debería evitar cualquier exageración y buscar el dorado término medio. Como refrán griego se conoce esto en la fórmula "meden agan»72. De igual modo que Alcocer critica el juego no como tal, sino como exageración mal utilizada, aconseja Ortiz una asistencia al teatro moderada, no desmesurada.

El contraste entre actividad y pasividad, que Diego de Estella ilustraba en el contexto de immanencia y trascendencia, de cuerpo y espíritu, fue completado por Pedro de Medina, quien identificaba la pereza con la muerte y los grandes hechos con la fama. El dormir se convertía en algo negativo, el estar despierto en algo positivo. Diego de Estella reafirmaba teológicamente su rechazo a la pasividad señalando la necesidad de rendir cuentas en el Juicio Final sobre la utilización provechosa del tiempo. Este tipo de criterios teológicos servían, como los humanistas, para enjuiciar los juegos de fortuna y los espectáculos. La cuestión de si el juego es bueno o es reprochable se resuelve también de forma diferente en uno u otro caso. Mientras que Mondragón rechaza los juegos de azar en su totalidad debido a su inmoralidad, Mariana condena de forma rigurosa los espectáculos por la misma razón. Frente a estas opiniones, figuran las posiciones moderadas que diferencian entre la cosa como tal y el uso que se hace de ella. De esta forma, Alcocer, Cobarrubias y Vives afirman que el juego de azar como tal no es malo. Dañino sería únicamente el hacer un mal uso de él. Lo mismo afirma Ortiz del teatro, con lo que, como Alcocer en referencia a las corridas de toros, pretende que se tenga en cuenta la intención que concurre, que podría legitimar una acción a priori desdeñable. La consideración de la intención tiene también una gran importancia en el enjuiciamiento de los juegos de fortuna. Todo dependería de si se pretende el entretenimiento o si se juega movido por la codicia, tal y como Alcocer y Torquemada aseguran. Si se juega con afán de ganar, escribe Vives en su introducción pedagógica para los jovenes, se pondría en peligro el valor de entretenimiento $\mathrm{y}$, con él, la única legitimación verdadera del juego.

Es común al enjuiciamiento de los juegos de fortuna y de los espectáculos el énfasis puesto en el significado del conjunto del Estado, que no debería ponerse en peligro, como Castillo de Bobadilla y Mariana así mismo muestran. Cuando Mondragón se refiere a los jugadores como a unos locos, no sólo sigue la tradición erasmista, sino que reflexiona sobre las consecuencias del juego para el Estado y la sociedad, de la

72 "Meden agan" se atribuye en general a los "siete sabios" y debió ser, según Platón («Hiparco» 228 E), una inscripción del templo de Apolo en Delfos. 
misma forma que Mariana atribuye prosperidad al Estado que, al igual que el romano, prohíbe las representaciones de teatro ${ }^{73}$.

El hecho de que los teólogos y humanistas tematizaran el fenómeno del juego tan frecuente y minuciosamente fue consecuencia de las contradicciones y las lagunas existentes en el derecho positivo, que, además, había sido en parte superado por el derecho consuetudinario. Para responder a preguntas no sólo sobre la apuesta en el juego, la legitimidad de la ganancia y la necesidad de su restitución, sino también sobre los límites de descuido del trabajo frente al derecho positivo se acudió a la Biblia, los teólogos de la Edad Media, las autoridades de la Antigüedad y el derecho natural. La casuística que de ello se derivaba contemplaba no sólo el lugar, momento y tipo de juego, sino también la posición social del participante en el juego. Tanto para los juegos de fortuna como para los espectáculos se reservó un estatus especial para los clérigos y las mujeres casadas, cuya participación parecía bastante discutible. Quien tiene muchas ocupaciones debería evitar, según Cobarrubias, el ajedrez, según Ortiz, la asistencia regular al teatro. Aquí se hace evidente que en el caso del teatro se cuestiona más que nada el papel del público. Aunque sin el público una representación de teatro no tendría mucho sentido, el espectador participa no directa, sino indirectamente en la obra de teatro. De forma parecida habían reflexionado también Alcocer y Cobarrubias acerca de la consideración del espectador en los juegos de fortuna, la culpa o la inocencia de los participantes indirectos, como los promotores de las casas de juego o los fabricantes de cartas.

Alcocer demostraba que el juego era considerado como un fenómeno complejo que implicaba a toda la sociedad, dentro del cual se podía diferenciar entre juegos de fortuna y espectáculos, y distinguía tres grupos: los juegos festivo-religiosos en días de fiesta, espectáculos profanos me-

73 Compárese también el artículo "Genève» en la Enciclopedia francesa del siglo XVIII, $\mathrm{t}$. XV, Denis Diderot, D'Alembert (ed.), Genève (Pellet) 1777, págs. 959-967, aquí pág. 963. En España se discute como en Francia la licitud del juego en el siglo XVIII con el trasfondo de la oposición entre la civilización y la barbarie. Esto lo comprueba la posición y la argumentación del catedrático de teología de la Universidad de Alcalá P. D. Alejandro Aguado que trabajó como censor para la inquisición: «Pues siendo las comedias juegos, muy arregladas á ella las escribieron Calderón, y Lope de Vega. San Clemente Alejandrino, con Aristóteles y Séneca, condena el modo de vivir austero, por poco civil, si no se templa con la sal de la diversión honesta, cuyas acciones son propias de la urbanidad, y se llama, rústico, duro, inurbano, é intratable, el que ni tiene alguna graciosidad, ni la sufre en los demás.» P. D. Alejandro Aguado, «Dictamen acerca del 'Discurso crítico sobre las comedias' de D. Tomás de Erauso y Zabaleta (1750)», en: Cotarelo y Mori, pág. 47. 
nos honrosos y juegos en sentido estricto, en los cuales diferenciaba según la proporción de capacidad y de casualidad. Ortiz sugería como alternativa a la asistencia al teatro la siesta, la visita de damas o el paseo por el centro de la ciudad. Para Alcocer, la alternativa a las corridas de toros serían las justas, correr sortija, la esgrima, el baile o las fiestas de máscaras. Las alternativas de Cobarrubias al juego eran: el deporte y pasatiempos como el baile, el juego de pelota, los torneos, leer libros y redactar sermones. A continuación, enumeraba el ajedrez, el baile, las apuestas, las fiestas, la música, los duelos, las fiestas de máscaras y la caza. Para Mariana, las opciones junto con el teatro eran: los banquetes, las corridas de toros, los placeres de la caza y las prostitutas. Las posibilidades de pasar el tiempo libre parecen, pues, muy diversas. El hecho de que en ellas los juegos de fortuna y los espectáculos se mencionen comparativamente al mismo nivel que las posibles alternativas se remonta claramente a la tradición medieval, en la que "tahures" y «juglares» iban juntos de un lado a otro y entretenían al público junto con saltinbanquis y "bufones». Las distintas esferas del uso del tiempo libre, a pesar de ser tan diferentes, podían ser enjuiciadas en el Siglo de Oro desde posiciones y a partir de criterios comparables como se ha ilustrado por medio de los juegos de fortuna y de los espectáculos. 